\title{
Relationships between land use and multi-dimensional characteristics of streams and rivers at two different scales
}

\author{
Se-Rin Park ${ }^{1}$, Hyun-Joo Lee ${ }^{1}$, Sang-Woo Lee ${ }^{1 *}$, Soon-Jin Hwang ${ }^{1}$, Myeong-Seop Byeon ${ }^{2}$, \\ Gea-Jae Joo ${ }^{3}$, Kwang-Seuk Jeong ${ }^{3}$, Dong-Soo Kong ${ }^{4}$ and Myoung-Chul Kim ${ }^{5}$ \\ 1 Department of Environmental Science, Konkuk University, Seoul 143-701, Republic of Korea \\ 2 Department of Water Management, The Environmental Research Institute, Inchon 404-708, Republic of Korea \\ 3 Department of Biological Sciences, Pusan National University, Pusan 609-735, Republic of Korea \\ 4 Department of Biology, Kyonggi University, Suwon 443-760, Republic of Korea \\ 5 SOKN Institute of Ecology \& Conservation, Seoul 110-034, Republic of Korea
}

Received 31 August 2010; Accepted 26 February 2011

\begin{abstract}
Despite numerous previous studies, relationships between watershed land use and adjacent streams and rivers at various scales in Korea remain unclear. This study investigated the relationships between land uses and the physical, chemical, and biological characteristics of 720 sites of streams and rivers across the country. The land uses at two spatial scales, including a 1-km buffer and the base watershed management region (BWMR), were computed in a geographical information system (GIS) with a digital land use/land cover map. Characteristics of land uses at two spatial scales were then correlated with the monitored multidimensional characteristics of the streams and rivers. The results of this study indicate that land use types have significant effects on stream and river characteristics. Specifically, most characteristics were negatively correlated with the proportions of urban, rice paddy, agricultural, and bare soil areas and positively correlated with the amount of forest. The site-scale and BWMR-scale analyses suggest that BWMR land use patterns were more strongly related to ecological integrity than they were to site land use patterns. Improving our understanding of land use effects will largely depend on relating the results of site-specific studies that use similar response techniques and measures to evaluate ecological integrity. In addition, our results clearly indicate that the characteristics of streams and rivers are closely linked and that land use types differentially affect those characteristics. Thus, effective restoration and management for ecological integrity of lotic system should consider the physical, chemical, and biological factors in combination.
\end{abstract}

Key words: Land use / lotic ecosystem / multi-dimensional characteristics / ecological integrity / restoration

\section{Introduction}

As human activities severely degrade the quality of surface water, the negative effects of watershed land use on adjacent streams and rivers are of increasing concern. Land use types within watersheds dictate the kinds of human activities that take place, which in turn determine the anthropogenic substances transported into hydrologic systems. Numerous studies have shown that water-quality characteristics are strongly affected by land use types and their relative proportions in watersheds (Lenat and Crawford, 1994; Sliva and Willams, 2001; Woli et al., 2004). For example, Arienzo et al. (2001) investigated the relationships between urbanization and water quality in the Sarno River basin, Italy, and reported a close

\footnotetext{
*Corresponding author: sw17311@konkuk. ac . kr
}

relationship between poor water quality and the growth of urban and industrial areas surrounding watersheds. Ren et al. (2003) also reported a strong negative correlation between agricultural areas and water-quality characteristics of adjacent streams, suggesting that chemical fertilizers from agricultural practices degrade water quality. Using the percentage of impervious areas as a key indicator of urbanization, Wang et al. (2001) reported that urban land uses had strong negative impacts on stream ecosystems. Tong and Chen (2002) demonstrated that land use types are correlated with most water-quality parameters in aquatic systems in Ohio, USA. Strong links between land use type and water-quality characteristics have been documented in several other aquatic systems (e.g., Omernik et al., 1981; Bolstad and Swank, 1997; Gburek and Folmar, 1999; Liu et al., 2000). Therefore, efforts to enhance water quality in streams and 
rivers clearly require appropriate watershed land use management.

Although previous studies have provided insight into the relationship between land use and water quality, the effects of land use on the characteristics of entire stream and river ecosystems remain unclear. To study this relationship, previous studies have mostly used physicochemical variables such as temperature, $\mathrm{pH}$, electronic conductivity (EC), biological oxygen demand (BOD), chemical oxygen demand (COD), turbidity, suspended solids, nitrogen groups (total nitrogen $[\mathrm{TN}], \mathrm{NH}_{4}-\mathrm{N}$, $\mathrm{NO}_{3}-\mathrm{N}, \mathrm{NO}_{2}-\mathrm{N}$ ), and phosphorus groups (total phosphorus [TP], $\mathrm{PO}_{4}-\mathrm{P}$ ), as well as several microbiological factors such as total coliform, fecal coliform, and Escherichia coli. Although these commonly used parameters are closely associated with the ecological characteristics of streams and rivers, individually, they do not provide insight into the entire ecosystem. Stream ecosystems are very complex and dynamic, making it difficult to characterize the system as a whole. Therefore, to better understand the impacts of land uses, one must integrate a wide range of indicators that capture diverse aspects of running water ecosystems. Biological indicators such as benthic diatoms, benthic macroinvertebrates, and fish can serve as particularly effective measures to assess the ecological characteristics of streams and rivers. Such indicators can be used to provide integrated evaluations of water quality and are closely tied to commonly used chemical indicators. According to the Korean Ministry of Environment (MOE/NIER, 2008), water-quality variables such as $\mathrm{BOD}, \mathrm{COD}, \mathrm{TN}, \mathrm{TP}$, and chlorophyll $a(\mathrm{Chl}-a)$ of streams and rivers are strongly correlated with the abundances of benthic diatoms, benthic macroinvertebrates, and fish in Korea. However, the relationships between chemical and biological indicators can vary, suggesting that chemical parameters may differentially affect species within aquatic ecosystems (MOE/NIER, 2008). Therefore, although biological indicators are not completely independent of other factors such as hydrogeochemical characteristics within streams and rivers, they can capture additional meaningful aspects that were overlooked by previous studies. In addition, physical habitat can be used as a primary indicator of the living space of instream biota (Maddock, 1999).

The use of biological indicators to characterize streams and rivers and examining the relationship between these indicators and land use is a fairly recent approach, which so far has shown promising results. For example, Beyene et al. (2009) reported that benthic diatoms are good indicators of pollution given that they are ubiquitous and immobile. Benthic macroinvertebrates have also played an important role in assessing the health of aquatic ecosystems (Rosenberg and Resh, 1993). Sharma and Rawat (2009) reported that the diversity and abundance of macroinvertebrates are good indicators of the overall health of wetlands. Moore and Palmer (2005) also found that invertebrate diversity was associated with agricultural and urbanized land use. The relationships between fish responses and urbanization have been studied less frequently than those between invertebrates and land use, although several studies have demonstrated that fish are negatively affected by urbanization (Meador et al., 2005; Steffy and Kilham, 2006; Utz et al., 2010). Previous studies, however, have not adequately assessed variation in biological indicators caused by land uses across an entire country including many different watersheds and different spatial scales. For example, the question of how different land uses (e.g., wetland, rice paddy, grasses, forest) within a region affect various biological characteristics at different scales remains unanswered.

The purpose of this study was to investigate the relationships between land uses and the multidimensional characteristics of streams and rivers including physical, chemical, and biological features at multiple scales. Over recent decades, the Korean government has been largely concerned about improving surface water quality, and in response, has made great efforts to regulate point-source pollutants. These efforts have only been partially successful (MOE/NIER, 2008) because their focus has been limited to the chemical aspects of aquatic systems and because we lack an understanding of the effects of nonpoint source pollutants, including land use, on water quality. Most regretfully, the concept of biological integrity was missing in the surface water management policy. The results of the present study will provide critical insights for the future management of land uses at a variety of scales (i.e., area, region, landscape, and nationwide) to enhance the ecological integrity of streams and rivers, as well as elsewhere.

\section{Materials and methods}

\section{Study area and scales}

The study area included the entire territory of Korea $\left(37^{\circ} 00^{\prime} \mathrm{S}-127^{\circ} 30^{\prime} \mathrm{E}\right.$; Fig. 1$)$, which occupies approximately 10003200 ha of the southern part of the Korean Peninsula. The average annual precipitation in Korea is $1324 \mathrm{~mm}$. Approximately two-thirds of the annual precipitation occurs in the summer (June-September), and the annual average temperature is $12.2^{\circ} \mathrm{C}$. Along with small independent streams, five major rivers (Han, Geum, Nakdong, Youngsan, and Seomjin rivers) span the entire country. Of these five rivers, the Han River has the largest river basin in Korea, occupying approximately one-quarter of the country.

The relative proportions of land use types within 1-km buffers from the sampling sites were computed in the geographical information system (GIS) for analysis at the site scale. Of the 720 sampling sites, only 649 were used in this study for availability of land use data. We selected $1-\mathrm{km}$ buffer zones to assess the direct impacts of land uses in riparian areas on stream characteristics. Riparian areas are regarded as ecotones, or boundary zones, separating two adjoining ecosystems, acting both as a conduit and a barrier to fluxes between them (Naiman and Decamps, 1990). Many previous studies have reported nutrient 
removal effects of riparian areas (Gilliam, 1994; Hill, 1996; Gilliam et al., 1997; Burt et al., 1999). In the 1990s, the term "riparian buffer zone" was originally established for managing non-point source pollution in the United States (Wenger, 1999). Since 1999, the MOE in Korea has established 1-km buffer zones for identifying critical areas nearby major rivers as a "limited development district" to protect the water quality of rivers. These riparian areas have played a significant role in managing pollutant input (Ban and Oh, 2010).

Based on river systems and watershed boundaries, the MOE in Korea has identified 117 base watershed management regions (BWMRs). Collectively, these BWMRs cover the entire country and have been used to formulate river-related policies, regulations, and budgets in Korea. Of the 117 BWMRs, 110 were used in this study for analysis; the remaining seven, which encompassed the demilitarized zone (DMZ), were excluded from analysis for security reasons. The proportions of land use types within the BWMR were computed using GIS. The average size of a BWMR was $916245.27 \mathrm{ha}$, and the average number of monitoring sites within a BWMR was 6.37. Thus, site-scale analysis is important for managing riparian areas protected by regulation, while BWMR-scale analysis can provide insights into non-point pollution and watershed management at a broader level than the site scale. The overall sizes and distributions of the BWMRs and monitoring sites are outlined in Figure 1.

\section{Sampling sites and indicators}

Sampling sites were selected based on the size of the river systems within the BWMRs, land uses, and specific stream management interests. The number of sampling sites for each of the five major rivers was 320 sites for the Han River, 130 sites for the Nakdong River, 130 sites for the Geum River, and 140 sites for the Youngsan and Seomjin rivers, respectively. Sampling at each site was conducted twice a year in the spring (April-May) and fall (September-October). Two sampling periods were selected to include seasonal variation and to avoid the summer rainy season. Each BWMR included different numbers of sampling sites. The unit of analysis in this study was a $1-\mathrm{km}$ buffer zone and the BWMR; thus, the assessed indicators within a BWMR were averaged and the values for the 1-km buffer zone were used.

Since 2007, as part of a Nationwide Aquatic Ecological Monitoring Program (NAEMP), the MOE has been monitoring multi-aspects of running waters, including chemical, physical, and biological characteristics, at longterm monitoring sites across the entire country. Under the monitoring program, the MOE has considered several assessment indices such as the trophic diatom index (TDI), Korean saprobic index (KSI), index of biotic integrity (IBI), a habitat-riparian indexing system (HIS), and a qualitative habitat evaluation index (QHEI). The monitoring program also included conventional waterquality variables. In this study, we focused on eight indicators: three biological indicators (benthic diatoms, benthic macroinvertebrates, and fish), two habitat indicators (HIS and QHEI), and three chemical indicators (BOD, TN, and TP). Detailed information of application and calculation of TDI, KSI, IBI, and HIS can be found in Lee et al. (2011) and other related works in this volume. For the calculation of QHEI, we followed the protocol of Rankin (1989).

\section{Land uses}

To calculate the proportions of land use within 1-km buffer zones and the BWMRs, we used the digital land use/land cover (LULC) map released by the Korean MOE. The LULC map was generated using the Landsat Thematic Mapper (TM; $30 \mathrm{~m}$ resolution) and Indian Remote Sensing (IRS)-1C panchromatic $(5.8 \mathrm{~m}$ resolution) images taken in 2007. According to the MOE classification, land use types were divided into seven categories, which were then further divided into 23 subcategories. The land uses were divided into seven main categories: urban areas, including industrial, residential, and commercial areas; agricultural areas; paddy areas; forested areas, including deciduous forest, coniferous forest, and mixed forest; grassy areas, including grassland and golf courses; wetlands; and bare soils, including mining areas. Paddy areas were defined as rice paddy fields filled with pond water for most of the growing season. Agricultural areas were relatively small upland agricultural lands used for the production of vegetables such as corn, soybeans, red peppers, and potatoes. The spatial analysis was conducted using ArcView, a vectorbased GIS software package. A boundary-shape file of each buffer and BWMR was overlaid with the LULC map to calculate the areas of land use within each 1-km buffer zone and BWMR, and the areas of each land use type within the $1-\mathrm{km}$ buffer zones and the BWMRs were converted to proportions for statistical analysis with indicators (TDI, KSI, IBI, HIS, QHEI, BOD, TN, and TP) representing multidimensional characteristics of streams and rivers.

\section{Results}

\section{Descriptive statistics at the site scale}

The values of TDI, KSI, BOD, TN, and TP are negative measures, such that higher values indicate poor ecological status and water degradation in streams. Conversely, IBI, HIS, and QHEI are positive measures, with higher values indicating better water conditions. The indicators of the aquatic systems greatly varied across the $1-\mathrm{km}$ buffer zones (Table 1). The means of the TDI, KSI, IBI, HIS, QHEI, BOD, TN, and TP were 56.5, 1.7, 21.3, $35.1,71.6,2.42,2.28$, and 0.12 , respectively. Given that the respective theoretical maximum values of TDI and KSI are 100 and 5.0, their maximum values (98.6 and 4.8, respectively) suggest that the overall lotic systems in Korea 


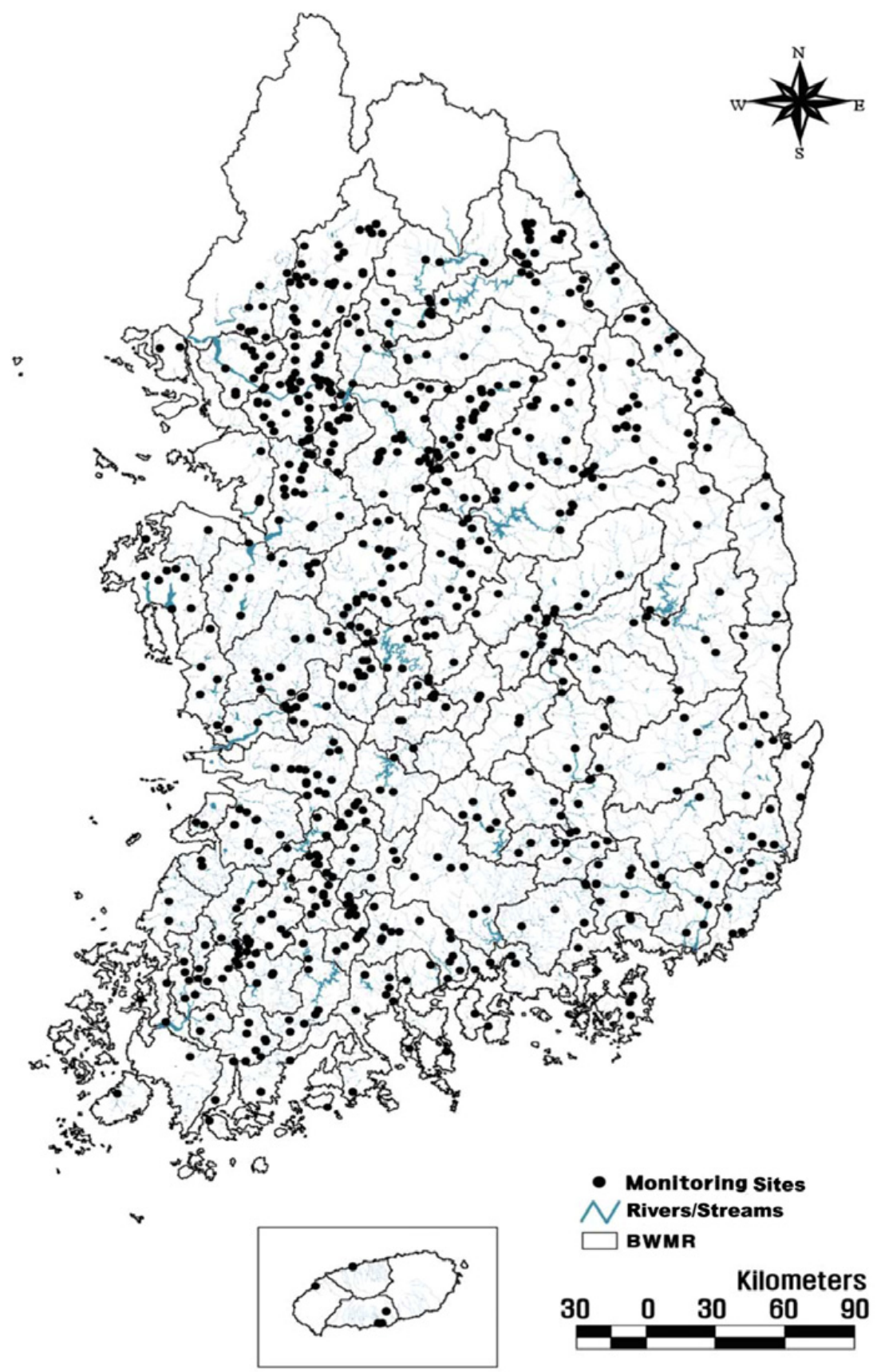

Fig. 1. A map showing the sampling sites and boundary of BWMRs.

were in poor condition. The maximum value of BOD (20.90) also confirmed impaired water conditions of monitored streams and rivers. IBI exhibited high variance, ranging from 8.0 to 40.0 across the $1-\mathrm{km}$ buffer zones, suggesting large differences between sites for fish assemblages.

The proportions of land use also varied over the $1-\mathrm{km}$ buffer zones (Table 1). The minimum values of all land use proportions were 0.00 , suggesting that the $1-\mathrm{km}$ buffer zones of some monitoring sites were dominated by few land use types. The mean proportion of bare soil was $0.05 \%$, indicating less bare soil in riparian areas. In contrast, forests accounted for a large proportion of riparian areas $(38.47 \%)$. Overall, forests, paddy areas, and agricultural and urbanized regions showed relatively high mean values, whereas the mean proportions of bare soil, wetlands, and grassy areas were intermediate.

\section{Descriptive statistics at the BWMR scale}

The quality indicators of aquatic systems varied greatly across the BWMRs (Table 1). The means of the TDI, KSI, IBI, HIS, QHEI, BOD, TN, and TP were 57.6, 1.7, $20.8,35.1,70.7,2.23,2.14$, and 0.09 , respectively. The distribution of indicators at the BWMR scale was similar 
Table 1. Descriptive statistics of multidimensional characteristics in Korean rivers/streams and proportion of land use types at the site scale and BWMR scale.

\begin{tabular}{|c|c|c|c|c|c|c|c|c|c|}
\hline \multirow{2}{*}{ Variables } & & \multicolumn{4}{|c|}{ Site scale } & \multicolumn{4}{|c|}{ BWMR scale } \\
\hline & & Min. & Max. & Mean & S.D. & Min. & Max. & Mean & S.D. \\
\hline \multirow[t]{3}{*}{ Biological indicators } & TDI & 20.8 & 98.6 & 56.5 & 17.9 & 28.6 & 87.7 & 57.6 & 14.0 \\
\hline & KSI & 0.0 & 4.8 & 1.7 & 1.2 & 0.4 & 4.6 & 1.7 & 0.9 \\
\hline & IBI & 8.0 & 40.0 & 21.3 & 7.3 & 12.5 & 34.0 & 20.8 & 5.3 \\
\hline \multirow[t]{2}{*}{ Physical indicators } & HIS & 14.0 & 50.0 & 35.1 & 5.9 & 23.0 & 45.8 & 35.1 & 4.1 \\
\hline & QHEI & 6.0 & 108.0 & 71.6 & 16.2 & 6.0 & 99.0 & 70.7 & 14.6 \\
\hline \multirow[t]{3}{*}{ Chemical indicators } & BOD & 0.17 & 20.90 & 2.42 & 1.85 & 0.21 & 7.43 & 2.23 & 1.14 \\
\hline & $\mathrm{TN}$ & 0.36 & 14.53 & 2.28 & 1.66 & 0.71 & 9.82 & 2.14 & 1.30 \\
\hline & TP & 0.00 & 2.82 & 0.12 & 0.21 & 0.00 & 0.41 & 0.09 & 0.09 \\
\hline \multirow[t]{7}{*}{ Land use (\%) } & Urban & 0.00 & 100.00 & 12.10 & 18.71 & 1.13 & 44.18 & 6.27 & 6.78 \\
\hline & Agricultural & 0.00 & 95.75 & 13.20 & 10.70 & 3.26 & 56.55 & 11.62 & 6.78 \\
\hline & Paddy & 0.00 & 97.93 & 28.15 & 24.08 & 0.10 & 42.12 & 14.62 & 9.73 \\
\hline & Forest & 0.00 & 99.03 & 38.47 & 26.54 & 12.85 & 89.02 & 58.74 & 17.09 \\
\hline & Grassland & 0.00 & 52.70 & 3.67 & 5.31 & 0.26 & 19.06 & 2.33 & 2.39 \\
\hline & Wetland & 0.00 & 40.58 & 4.35 & 4.78 & 0.00 & 10.68 & 1.10 & 1.50 \\
\hline & Bare soil & 0.00 & 4.45 & 0.05 & 0.38 & 0.14 & 6.79 & 1.61 & 1.08 \\
\hline
\end{tabular}

$n=649$ (site scale), $n=110$ (BWMR scale).

TDI, trophic diatom index; KSI, Korean saprobic index; IBI, index of biotic integrity; HIS, habitat-riparian indexing system;

QHEI, qualitative habitat evaluation index; BOD, biochemical oxygen demand; TN, total nitrogen; TP, total phosphorus.

to that at the site scale. However, the maximum values of seven indicators at the BWMR scale were much lower than those at the site scale, likely because the values of the indicators at the site scale were aggregated into a larger spatial scale (i.e., BWMRs).

The proportions of land use also varied over the BWMRs. In particular, forests showed great variation, ranging from 12.85 to $89.02 \%$. In contrast, the proportion of bare soil varied over a much smaller range $(0.14$ $6.79 \%$ ). The proportion of urbanized areas ranged from 1.13 to $44.18 \%$, suggesting that the degree of urbanization varied widely among the BWMRs. The mean areas of the proportions of bare soil, forest, urban, paddy, agricultural, wetland, and grassy areas were 1.60, 58.74, 6.37, $11.62,14.62,1.10$, and $2.33 \%$, respectively. Overall, forests, paddy areas, and agricultural areas exhibited relatively higher mean values, whereas the mean proportions of bare soil, wetlands, and grassy areas had intermediate values.

\section{Relationships between stream characteristics and land use at the site scale}

The proportions of land use were correlated with the seven indicators measured at the site scale in Table 2. At the site scale, the proportion of urbanized areas was positively correlated with TDI $(r=0.34)$, KSI $(r=0.41)$, BOD $(r=0.24)$, TN $(r=0.26)$, and TP $(r=0.23)$, and negatively correlated with IBI $(r=-0.31)$, HIS $(r=$ $-0.52)$, and QHEI $(r=-0.16)$. These results suggest that a higher degree of urbanization was associated with poor aquatic biological conditions. Note that the proportion of agricultural areas was significantly related to only three indicators, KSI $(r=-0.10)$, IBI $(r=0.09)$, and TN $(r=0.09)$. The correlation coefficient was also very low, suggesting weak relationships between agricultural areas and the indicators. The proportion of paddy areas was significantly correlated with TDI $(r=0.25)$, KSI $(r=0.28)$, IBI $(r=-0.36)$, QHEI $(r=-0.22)$, BOD $(r=0.26)$, TN $(r=0.09)$, and TP $(r=0.09)$. The contrasting relationships between agricultural and paddy areas may have been due to differences in the proximity of these areas to streams and rivers, farming intensity, and type of crop, as well as fertilization frequency and intensity. However, more detailed studies are needed to clarify this result.

The proportion of forested areas was significantly associated with all indicators in Table 2, particularly KSI $(r=-0.52)$ and IBI $(r=-0.58)$, but also TDI $(r=$ $-0.40)$, HIS $(r=0.41)$, QHEI $(r=0.33)$, BOD $(r=$ $-0.41)$, TN $(r=-0.32)$, and TP $(r=-0.27)$. These results confirmed previous findings suggesting strong positive links between forested areas and indicators of streams. The proportion of grassy areas was also positively correlated with KSI $(r=0.14)$ and negatively correlated with IBI $(r=-0.18)$, HIS $(r=-0.16)$; however, grassy areas were not significantly related to other indicators. These results contrast with those of previous studies reporting positive effects of grass areas on water quality (Nakamura et al., 2001; Anbumozhi et al., 2005). The proportion of wetlands was positively correlated with KSI $(r=0.13)$ and BOD $(r=0.10)$ and negatively correlated with IBI $(r=-0.30)$. In this study, the bare soil land use type was not significantly related to all indicators due to extremely low proportions of base soils within riparian areas (i.e., 1-km buffer zones).

\section{Relationship between stream characteristics and land use at the BWMR scale}

The proportions of land use were correlated with the indicators measured at the BWMR scale and the results 
Table 2. Spearman rank correlation coefficients between land use and indicators at the site scale.

\begin{tabular}{|c|c|c|c|c|c|c|c|c|}
\hline \multirow{2}{*}{ Indicators } & & \multicolumn{7}{|c|}{ Land use types } \\
\hline & & Urban & Agricultural & Paddy & Forest & Grass & Wetland & Bare soil \\
\hline \multirow[t]{3}{*}{ Biological indicators } & TDI & $0.20 * *$ & 0.03 & $0.25^{* *}$ & $-0.40 * *$ & 0.07 & 0.06 & 0.07 \\
\hline & KSI & $0.35 * *$ & $-0.10^{*}$ & $0.28 * *$ & $-0.52 * *$ & $0.14 * *$ & $0.13 * *$ & 0.03 \\
\hline & IBI & $-0.31 * *$ & $0.09 *$ & $-0.36 * *$ & $0.58 * *$ & $-0.18 * *$ & $-0.30 * *$ & 0.05 \\
\hline \multirow[t]{2}{*}{ Physical indicators } & HIS & $-0.52 * *$ & 0.06 & 0.04 & $0.41 * *$ & $-0.16^{* *}$ & 0.00 & 0.02 \\
\hline & QHEI & $-0.16^{* *}$ & 0.04 & $-0.22 * *$ & $0.33 * *$ & 0.01 & 0.05 & 0.01 \\
\hline \multirow[t]{3}{*}{ Chemical indicators } & BOD & $0.24 * *$ & 0.06 & $0.26^{* *}$ & $-0.41 * *$ & 0.06 & $0.10 *$ & 0.05 \\
\hline & $\mathrm{TN}$ & $0.26 * *$ & $0.09 *$ & $0.09 *$ & $-0.32 * *$ & 0.07 & 0.03 & 0.05 \\
\hline & $\mathrm{TP}$ & $0.23 * *$ & 0.00 & $0.09 *$ & $-0.27 * *$ & 0.05 & 0.07 & 0.03 \\
\hline
\end{tabular}

$* P<0.05, * * P<0.01, n=649$.

TDI, trophic diatom index; KSI, Korean saprobic index; IBI, index of biotic integrity; HIS, habitat-riparian indexing system;

QHEI, qualitative habitat evaluation index.

Table 3. Spearman rank correlation coefficients between land use and indicators at the BWMR scale.

\begin{tabular}{|c|c|c|c|c|c|c|c|c|}
\hline \multirow[b]{2}{*}{ Indicators } & & \multicolumn{7}{|c|}{ Land use type } \\
\hline & & Urban & Agricultural & Paddy & Forest & Grass & Wetland & $\overline{\text { Bare soil }}$ \\
\hline \multirow[t]{3}{*}{ Biological indicators } & TDI & $0.34 * *$ & $0.42 * *$ & $0.35 * *$ & $-0.62 * *$ & $0.26^{* *}$ & 0.14 & $0.28 * *$ \\
\hline & KSI & $0.41 * *$ & 0.11 & $0.42 * *$ & $-0.61^{* *}$ & -0.02 & $0.36^{* *}$ & $0.41 * *$ \\
\hline & IBI & $-0.31 * *$ & -0.12 & $-0.60 * *$ & $0.56^{* *}$ & 0.09 & $-0.31 * *$ & $-0.25^{* *}$ \\
\hline \multirow[t]{2}{*}{ Physical indicators } & HIS & $-0.38 * *$ & $-0.35^{* *}$ & -0.16 & $0.51 * *$ & $-0.38 * *$ & -0.08 & $-0.31 * *$ \\
\hline & QHEI & -0.10 & $-0.21 * *$ & $-0.30 * *$ & $0.43 * *$ & 0.06 & $-0.22 *$ & $-0.30 * *$ \\
\hline \multirow[t]{3}{*}{ Chemical indicators } & BOD & $0.54 * *$ & -0.00 & $0.44 * *$ & $-0.54 * *$ & -0.08 & $0.47 * *$ & $0.28 * *$ \\
\hline & $\mathrm{TN}$ & $0.40 * *$ & $0.53 * *$ & 0.09 & $-0.55^{* *}$ & $0.49 * *$ & $0.25 * *$ & $0.19 *$ \\
\hline & $\mathrm{TP}$ & $0.52 * *$ & 0.17 & $0.30 * *$ & $-0.52 * *$ & $0.20 *$ & 0.14 & $0.20 *$ \\
\hline
\end{tabular}

$* P<0.05, * * P<0.01, n=110$.

TDI, trophic diatom index; KSI, Korean saprobic index; IBI, index of biotic integrity; HIS, habitat-riparian indexing system;

QHEI, qualitative habitat evaluation index.

are summarized in Table 3. At the BWMR scale, the proportion of urbanized areas was positively correlated with TDI $(r=0.34)$, KSI $(r=0.41)$, BOD $(r=0.54)$, TN $(r=0.40)$, and TP $(r=0.52)$ and negatively correlated with IBI $(r=-0.31)$ and HIS $(r=-0.38)$. These results suggest that a higher degree of urbanization was associated with poor biological, physical, and chemical conditions. The QHEI was not significantly related to the proportions of urbanized areas. The proportion of agricultural areas was significantly related to only four indicators: TDI $(r=0.42)$, HIS $(r=-0.35)$, QHEI $(r=-0.21)$, and TN $(r=0.53)$. The proportions of agricultural areas within BWMRs appeared to be associated with particular biological indicators (i.e., TDI) and physical conditions. The proportion of paddy areas was significantly correlated with TDI $(r=0.35)$, KSI $(r=0.42)$, IBI $(r=-0.60)$, QHEI $(r=-0.30)$, BOD $(r=0.44)$, and TP $(r=0.30)$ in Table 5. These results indicated that poor biological conditions were prevalent if the BWMR contained more paddy areas. The proportion of forested area was significantly correlated with all indicators, particularly with TDI $(r=-0.62)$, KSI $(r=-0.61)$, IBI $(r=0.56)$, HIS $(r=0.51)$, QHEI $(r=0.43)$, BOD $(r=-0.54)$, TN $(r=-0.55)$, and TP $(r=-0.52)$. The biological conditions of streams are likely better if watersheds exhibit substantial forest cover. The proportion of grass areas was positively correlated with TDI $(r=0.23)$, TN $(r=0.49)$, and TP $(r=0.20)$ and negatively correlated with HIS $(r=-0.38)$; however, grass areas were not significantly related to KSI, IBI, QHEI, or BOD. The proportion of wetlands was positively correlated with KSI $(r=0.36)$, BOD $(r=0.47)$, and TN $(r=0.25)$ and negatively correlated with IBI $(r=-0.31)$ and QHEI $(r=-0.22)$. However, TDI, HIS, and TP were not significantly related to wetland areas. The negative effects of grass areas and wetlands in the BWMRs are somewhat in conflict with previous studies that suggest positive contributions of grass areas and wetlands to the water quality of adjacent streams (Anbumozhi et al., 2005). In this study, the bare soil land use type contained wastelands and mining areas. These areas were related to TDI $(r=0.28)$, KSI $(r=0.41)$, IBI $(r=-0.25)$, HIS $(r=-0.31)$, QHEI $(r=-0.30)$, BOD $(r=0.28)$, TN $(r=0.19)$, and TP $(r=0.20)$. We found that areas of bare soil negatively affected the biological condition of streams.

\section{Discussion}

\section{Land use effects on the ecological integrity of streams and rivers}

The results of this study show that urban areas negatively impact the ecological conditions of streams 
and rivers, and this finding was consistent over the multiple scales examined. Our results are in accordance with those of previous studies, suggesting strong links between high levels of urbanization within watersheds and impaired ecological and chemical conditions of aquatic systems (Lenat and Crawford, 1994; Ren et al., 2003; Moore and Palmer, 2005). Recently, Moore and Palmer (2005) reported that invertebrate diversity declined as urbanization increased. Several other studies also reported that fish parameters tend to decline with increasing impervious surface cover due to urbanization (Weaver and Garman, 1994; Wang et al., 1997). Furthermore, Lenat and Crawford (1994) reported that urban streams exhibited lower species richness than both forested and agricultural streams. Combined, the findings of previous studies and the results of this study strongly suggest that managing urban areas at both the site scale (riparian areas) and the BWMR scale (watershed areas) is essential to sustain the ecological integrity of streams and rivers. In this regard, the proportion of urbanized areas in riparian areas or watersheds can be a good predictor of the chemical or ecological characteristics of a stream (Allan, 2004).

Significant relationships were detected between agricultural areas and four indicators, including TDI, HIS, QHEI, and TN at the BWMR scale, whereas no significant relationships were found between any indicators and agricultural areas at the site scale. Some significant relationships were detected between agricultural land use and the monitored indicators (i.e., TDI, IBI, and TN), although the relationships are modest at best. Thus, agricultural areas, on a broad scale, appear to be more significant variables when assessing the ecological integrity of streams and rivers than those that are more specific to the site scale. Many studies have reported negative impacts of agricultural areas in watersheds on the ecological communities of streams. For example, periphyton communities tend to increase in agricultural streams due to high nutrient loading (e.g., Lenat and Crawford, 1994), as agricultural runoff often leads to the enrichment of nutrients that can include toxic chemicals such as pesticides. Agricultural activities are considered as key contributors to nitrogen pollution in the environment (Cooper, 1993), and numerous studies have also noted that agricultural land use in upland areas is a main source of the nutrient enrichment of aquatic systems (Lenat and Crawford, 1994; Gardi, 2001; Woli et al., 2004). Gardi (2001) found that agricultural areas also strongly affect water quality due to high concentrations of nutrient and chemical inputs. However, in this study, agricultural areas were not significantly related to BOD, whereas paddy areas appeared to negatively affect BOD. Overall, the results of this study confirmed the findings of previous studies indicating negative impacts of agricultural land at the BWMR scale. Conversely, our results were not consistent with those of previous studies at the site scale. As discussed earlier, the discrepancy between this study and previous ones regarding the effects of agricultural areas on stream BOD concentrations is due in part to differences in land use classification, land use intensity, farming practices, crop types, and the intensity of fertilizer use. Agricultural areas in this study are mostly located on hillsides, relatively separate from streams, and include small plots. At the site scale, farmers raise corn, beans, peppers, and potatoes for self-consumption with less intense fertilizer and pesticide use. Assessing the features of agricultural areas enables the separation of the physical conditions of watersheds and human activities (e.g., water use, fertilizers, and pesticides) in a given area. Differences in the human activities (e.g., farming practices) as indicated by the relative proportion of agricultural areas in the riparian zones and watersheds likely caused the discrepancies between our findings and those reported previously, particularly at the site scale. For these reasons, the relative amount of agricultural area may not be an appropriate variable for predicting the ecological integrity of streams in Korea. Thus, one must be cautious when investigating the relationships between agricultural areas and water characteristics and comparing the results with other studies due to scale effects and different definitions of agricultural land use.

The proportion of paddy areas had a strong negative effect on almost all indicators. In addition to our study, several previous studies have reported negative effects of paddy areas on stream water quality (Jung et al., 2008), whereas other studies have suggested that paddy areas can ameliorate pollution effects (Nakamura et al., 2001). Paddy areas are rice fields filled with pond water, and they are typically located in low-lying areas with neighboring streams. Farmers cultivate rice for commercial purposes in Korea, thus using substantial amounts of fertilizers, pesticides, and herbicides. In contrast, agricultural areas are composed of relatively small, upland agricultural lands used for the production of vegetables such as red peppers, carrots, and potatoes, primarily for individual use. Typically, agricultural areas in upper areas are located far from streams. Thus, compared with upland agricultural areas, the chemically intense cultivation of lowland paddy areas more directly affects the water quality of nearby streams.

Forest areas were strongly related with all indicators. These results support previous findings, which suggested strong positive links between forested areas and biological indicators of streams. For example, Wallace et al. (1997) reported that the removal of trees in forested areas negatively affected stream invertebrate communities. Moore and Palmer (2005) demonstrated that the biodiversity of macroinvertebrates in forested streams was higher than that in urban streams. The positive effects of riparian forest buffer zones on water quality are well known. Forested land use also plays a role in mitigating poor water quality (Sliva and Willams, 2001). Multiple studies have reported that forested areas are important in filtering pollutants caused by runoff (Baker, 2003; Nygoye and Machiwa, 2004). Anbumozhi et al. (2005) reported that riparian forests areas have positive effects on water quality. In addition, many previous studies (Omernik et al., 1981; Bolstad and Swank, 1997; Liu et al., 2000) 
showed that forest area was positively related with BOD, TN, TP, and E. coli.

We found that grassy areas were negatively related to the indicators examined. However, a positive role of grassy areas as well as forests in filtering runoff pollutants of stream systems has been widely accepted (Baker, 2003; Nygoye and Machiwa, 2004). Similarly, Sliva and Willams (2001) demonstrated that both field and forested buffer zones reduce pollutant levels. However, grassy areas in this study included golf courses, urban parks, and urban fringe areas, and the overall proportion of grassy areas was intermediate at best. In 2008, Korea was home to 280 golf courses, occupying $0.3 \%$ of the entire country. Osborne and Kovacic (1993) found that grassy buffers led to lower reductions of pollutant concentrations compared to forested buffers. Thus, the filtering effects of grassy areas tend to be less than that of forests; indeed, artificial grassy areas may even exacerbate the biological deterioration of streams. To more accurately determine the role of grassy areas, this land use type should be divided into natural and artificial areas.

At the site scale, with the exceptions of KSI, IBI, and BOD, most indicators exhibited non-significant relationships with wetlands. In addition, at the BWMR, TDI, HIS, and TP were not significantly associated with wetlands; although wetlands negatively affected KSI, IBI, QHEI, BOD, and TN. These results are in contrast with those of previous studies, likely because wetlands only occupy a small portion of the total area in Korea. If only the effects of wetlands had been examined, these systems would have likely exhibited a positive role in stream ecosystem health. However, in this study, because wetlands occupied a relatively smaller area than the other land use types examined, our results indicated no link between the indicators tested and wetlands.

Our results showed that bare soil areas negatively impact all indicators at the BWMR scale. In contrast, the site-scale analysis showed no apparent relationship between bare soil areas and all indicators examined. In Korea, bare soil areas include mining areas and wastelands. Numerous previous studies have reported that mining negatively impacts benthic diatoms, macroinvertebrates, and fish communities (Tkatcheva et al., 2004; MacCauslanda and McTammany, 2007; Morin et al., 2008).

The results of the correlation analysis at both the site scale and the BWMR scale were similar. However, our results suggest that BWMR land use patterns were more strongly related to ecological integrity than site land use patterns. Some previous studies testing scale influences report that whole-catchment land use patterns are better predictors of stream ecological integrity (Frissell et al., 1986; Poff and Ward, 1990), while others suggest that riparian land use patterns are more influential (Davies and Nelson, 1994; Lammert and Allan, 1999). Thus, the effects of land use on ecological indicators are somewhat controversial. In this study, the BWMR scale is a reflection of the whole catchment, while the site scale includes only riparian zones. Our study supports that BWMR land use patterns are more strongly related to the ecological integrity of the stream than site land use patterns.

\section{Conclusions}

In this study, we explored the relationships between stream characteristics including physical, biological, and chemical indicators and land use at multiple spatial scales. Land use/land cover was computed using a LULC map generated by the Korean MOE using GIS at the site and BWMR scales. Monitoring data from each sampling of the NAEMP were averaged over each BWMR. Despite the lack of data regarding site-specific phenomena, understanding the complex relationships between land use and indicators at the site scale and BWMR scale will provide valuable insights for developing effective riparian and watershed management policies.

The results of the study strongly highlight the negative impacts of human-induced land use types on various characteristics of streams and rivers. In particular, urbanized areas posed strong negative effects within watersheds. Bare soil and paddy areas also appeared to negatively affect the biological condition of streams. However, the effect of paddy areas on streams may depend on the sampling season as well as farming practices such as fertilization, irrigation, and pesticide application, which vary throughout the year. In addition, more detailed information is needed concerning the relationship between agricultural areas and water quality. In Korea, agricultural and paddy areas clearly differ in terms of farming purposes and practices, proximity to streams, crops, irrigation frequency, and topography. In the present study, the negative effects of paddy areas on aquatic ecosystems were stronger than those of agricultural areas. In contrast, the effects of grassy areas and wetlands on the conditions of streams were not clear. At the present study sites, both grassy areas and wetlands were artificially constructed by humans and were not natural areas. Overall, forests had a consistently positive effect on the conditions of streams in the correlation analysis. Our results clearly indicate that the characteristics of streams are closely linked and that different land use types differentially affect the characteristics of streams at different scales. Thus, effective restoration and management for ecological stream integrity should consider physical, chemical, and biological factors in combination. In addition, whole-catchment land use patterns had stronger effects on the stream and river characteristics than the riparian buffer zone land use pattern. These results suggest that stream and river management that considers watershed-dimensional rather than riparian buffer zone data is needed for improving stream health. However, these results are somewhat controversial given that they are in conflict with those of some previous studies. Thus, additional investigations are needed to examine the influence of each land use type within 1-km buffer zones and at the BWMR scale.

Several important watershed characteristics that may affect the relationship between land use and stream 
and river indicators (e.g., vegetation, surface geology, and landscape characteristics) were not considered in this study. We also suggest that longitudinal studies of changes in biological indicators should be a priority. Consistent monitoring of changes in indicators will help to identify how land use planning can ensure the preservation of water resources. For efficient monitoring, adequate sampling frequency is important. Further investigations will require better spatial and temporal sampling data and higher-resolution digital maps with more land use classes. In this study, the land use classification was based on a 2007 map; however, the water-quality characteristics and biological indicator database contained 2009 data. In the MOE land use classification, the seven categories used in this study were further divided into 23 subcategories. For example, urbanized areas were subdivided into residential, commercial, and industrial areas; however, the effects of these sub-factors could not be isolated in this study. Each effect of residential, commercial, and industrial areas is definitely different. Thus, additional research is needed to resolve such issues and obtain more accurate results. Finally, further studies are needed to examine the influence of more specific land use types and how land uses are distributed within the watershed.

Acknowledgements. This study was financially supported by the Ministry of Environment and the National Institute of Environmental Research (Korea), and the results of this study form part of the "Survey and valuation of Aquatic Ecosystem Health in Korea, 2009". The authors would like to thank all of survey members involved in the project, for their help in the samplings and analyses. We also thank reviewers for their invaluable comments in improving the quality of the manuscript.

\section{References}

Allan J.D., 2004. Landscapes and riverscapes: the influence of land use on stream ecosystems. Annu. Rev. Ecol. Evol. Syst., 35, 257-284.

Anbumozhi V., Radhakrishnan J. and Yamaji E., 2005. Impact of riparian buffer zones on water quality and associated management considerations. Ecol. Eng., 24, 517-523.

Arienzo M., Adamo P., Bianco M.R. and Violante P., 2001. Impact of land use and urban runoff on the contamination of the Sarno River basin in Southwestern Italy. Water Air Soil Pollut., 131, 349-366.

Baker A., 2003. Land use and water quality. Hydrol. Process., 17, 2499-2501.

Ban S. and Oh C.H., 2010. A development of landscape ecological model for priority setting gereen space on riparian zone. Proc. Korean Environ. Ecol. Conf., 20, 113-117 (in Korean).

Beyene A., Addis T., Kifle D., Legesse W., Kloos H. and Triest L., 2009. Comparative study of benthic diatom and macroinvertebrates as indicators of severe water pollution: case study of the Kebena and Akaki Rivers in Addis Ababa, Ethiopia. Ecol. Ind., 9, 381-392.

Bolstad P.V. and Swank W.T., 1997. Cumulative impacts of land use on water quality in a southern Appalachian watershed. J. Am. Water Res. Assoc., 33, 519-533.
Burt T.P., Matchett L.S., Goulding K.W.T., Webster C.P. and Haycock N.E., 1999. Denitrification in riparian buffer zones: the role of floodplain hydrology. Hydrol. Process., 13, 1451-1463.

Cooper A.B., 1993. Coupling wetland treatment to land treatment: an innovative method for nitrogen stripping. Water Sci. Tech., 29, 141-149.

Davies P.E. and Nelson M., 1994. Relationship between riparian buffer widths and the effects of logging on stream habitat, invertebrate community composition, and fish abundance. Aust. J. Marine Freshwater Res., 45, 1289-1305.

Frissell C.A., Liss W.J., Warren C.E. and Hurley M.D., 1986. A hierarchical framework for stream habitat classification: viewing streams in a watershed context. Environ. Manage., $10,199-214$.

Gardi C., 2001. Land use, agronomic management and water quality in a small Northern Italian watershed. Agric. Ecosyst. Environ., 87, 1-12.

Gburek W.J. and Folmar G.J., 1999. Flow and chemical contributions to stream flow in an upland watershed: a baseflow survey. J. Hydrol., 217, 1-18.

Gilliam J.W., 1994. Riparian wetlands and water quality. J. Environ. Qual., 23, 896-900.

Gilliam J.W., Parsons J.E. and Mikkelsen R.L., 1997. Nitrogen dynamics and buffer zones. In: Haycock N.E., Burt T.P., Goulding K.W.T. and Pinay G. (eds.), Buffer Zones: Their Processes and Potential in Water Protection, Quest Environmental, Harpenden, 54-61.

Hill A.R., 1996. Nitrate removal in stream riparian zones. J. Environ. Qual., 25, 743-755.

Jung K.W., Lee S.W., Hwang H.S. and Jang J.H., 2008. The effects of spatial variability of land use on stream water quality in a coastal watershed. Paddy Water Environ., 6, 275284.

Lammert M. and Allan J.D., 1999. Assessing biotic integrity of streams: effects of scale in measuring the influence of land use/cover and habitat structure on fish and macroinvertebrates. J. Environ. Manage., 23, 257-270.

Lee S.W., Hwang S.J., Lee J.K., Jung D.I., Park Y.J. and Kim J.T., 2011. Overview and application of the National Aquatic Ecological Monitoring Program (NAEMP) in Korea. Ann. Limnol. - Int. J. Limnol., 47, S3-S14.

Lenat D.R. and Crawford J.K., 1994. Effects of land use on water quality and aquatic biota of three North Carolina Piedmont streams. Hydrobiologia, 294, 185-199.

Liu A.J., Tong S.T.Y. and Goodrich J.A., 2000. Land use as a mitigation strategy for the water-quality impacts of global warming: a scenario analysis on two watersheds in the Ohio River Basin. Environ. Eng. Policy, 2, 65-76.

MacCauslanda A. and McTammany M.E., 2007. The impact of episodic coal mine drainage pollution on benthic macroinvertebrates in streams in the anthracite region of Pennsylvania. Environ. Pollut., 149, 216-226.

Maddock I., 1999. The importance of physical habitat assessment for evaluating river health. Freshwater Biol., 41, 373-391.

Meador M.R., Coles J.F. and Zappia H., 2005. Fish responses to urban intensity gradients in contrasting metropolitan areas: Birmingham, Alabama and Boston, Massachusetts. Am. Fish. Soc. Symp., 47, 409-423.

MOE/NIER, 2008. Survey and evaluation of aquatic ecosystem health in Korea, The Ministry of Environment/National Institute of Environmental Research, Korea (in Korean). 
Moore A.A. and Palmer M.A., 2005. Invertebrate biodiversity in agricultural and urban headwater streams: implications for conservation and management. Ecol. Appl., 15, 1169-1177.

Morin S., Duonga T.T., Dabrin A., Coynel A., Herloryb O., Baudrimont M., Delmas F., Durrieu G., Schäfer J., Winterton P., Blanc G. and Coste M., 2008. Long-term survey of heavy-metal pollution, biofilm contamination and benthic diatom community structure in the Riou Mort watershed, south-west France. Environ. Pollut., 151, 532-542.

Naiman R.J. and Decamps H., 1990. The Ecology and Management of Aquatic-Terrestrial Ecotones, Parthenon Press, UNESCO, Paris.

Nakamura K., Nakayama H., Hideshma Y., Ishida T., Ogikibo J. and Moriwaki S., 2001. Drainage flows in grass and forest slope lands. In: Proceedings of the JSIRDE Annual Meeting, 44-45.

Nygoye E. and Machiwa J.F., 2004. The influence of land-use patterns in the Ruvu River watershed on water quality in the river system. Phys. Chem. Earth Sci., 29, 1161-1166.

Omernik J.M., Abernathy A.R. and Male L.M., 1981. Stream nutrient levels and proximity of agricultural and forest land to streams: some relationships. J. Soil Water, 36, 227-231.

Osborne L.L. and Kovacic D.A., 1993. Riparian vegetated buffer strips in water-quality restoration and stream management. Freshwater Biol., 9, 243-258.

Poff N.L. and Ward J.V., 1990. The physical habitat template of lotic systems: Recovery in the context of historical pattern of spatio-temporal heterogeneity. Environ. Manage., 14, 629-646.

Rankin E.T., 1989. The Qualitative Habitat Evaluation Index: (QHEI); Rationale, Methods, and Application, Environmental Protection Agency.

Ren W., Zhong Y., Meligrana J., Anderson B., Watt W.E., Chen J. and Leung H., 2003. Urbanization, land use, and water quality in Shanghai 1947-1996. Environ. Int., 29, 649-659.

Rosenberg D.M. and Resh V.H., 1993. Introduction to Freshwater Biomonitoring and Benthic Macroinvertebrates, Chapman and Hall, New York, 194 p.
Sharma R.C. and Rawat J.S., 2009. Monitoring of aquatic macroinvertebrates as bioindicators for assessing the health of wetlands: a case study in the Central Himalayas, India. Ecol. Ind., 9, 118-128.

Sliva L. and Willams D.D., 2001. Buffer zone versus whole catchment approaches to studying land use impact on river water quality. Water Res., 35, 3462-3472.

Steffy L.Y. and Kilham S.S., 2006. Effects of urbanization and land use on fish communities in Valley Creek watershed, Chester County, Pennsylvania. Urban Ecosyst., 9, 119-133.

Tkatcheva V., Hyvärinen H., Kukkonen J., Ryzhkov L.P. and Holopainen I.J., 2004. Toxic effects of mining effluents on fish gills in a subarctic lake system in NW Russia. Ecotoxicol. Environ. Safety, 57, 278-289.

Tong S. and Chen W., 2002. Modeling the relationship between land use and surface water quality. J. Environ. Manage., 66, 377-393.

Utz R.M., Hilderbrand R.H. and Raesly R.L., 2010. Regional differences in patterns of fish species loss with changing land use. Biol. Conserv., 143, 688-699.

Wallace J.B., Eggert S.L., Meyer J.L. and Webster J.R., 1997. Multiple trophic levels of a forest stream linked to terrestrial litter inputs. Science, 277, 102-104.

Wang L., Lyons J., Kanehl P. and Gatti R., 1997. Influences of watershed land use on habitat quality and biotic integrity in Wisconsin streams. Fisheries, 22, 6-12.

Wang L., Lyons J., Kanehl P. and Bannerman R., 2001. Impacts of urbanization on stream habitat and fish across multiple spatial scales. Environ. Manage., 28, 255-266.

Weaver A.L. and Garman G., 1994. Urbanization of a watershed and historical changes in a stream fish. Trans. Am. Fish. Soc., $123,162-172$.

Wenger S., 1999. A Review of the Scientific Literature on Riparian Buffer Width, Extent and Vegetation, Office of Public Service \& Outreach Institute of Ecology, University of Georgia.

Woli K.R., Nagumo T., Kuramochi K. and Hatano R., 2004. Evaluating river water quality through land use analysis and $\mathrm{N}$ budget approaches in livestock farming areas. Sci. Total Environ., 329, 61-74. 